\title{
The Influence of Dental Trauma Education on Undergraduate Students at Ajman University, United Arab Emirates: An Interventional Study
}

\author{
Raghad Hashim (1) \\ Ruba Odeh (D) $^{2}$ \\ Afraa Hussain Salah (iD ${ }^{2}$ \\ Simy Mathew iD ${ }^{3}$ \\ 'Department of Basic Medical and Dental \\ Sciences, Centre of Medical and Bio- \\ Allied Health Sciences Research, Ajman \\ University, Ajman, United Arab Emirates; \\ ${ }^{2}$ Department of Clinical Sciences, Ajman \\ University, Ajman, United Arab Emirates; \\ ${ }^{3}$ Department of Basic Medical and Dental \\ Sciences, Ajman University, Ajman, \\ United Arab Emirates
}

Background and Objectives: The main objective of this study was to assess the impact of a lecture on dental trauma on the knowledge of undergraduate dental students at Ajman University in the United Arab Emirates (UAE).

Methods: Fourth-year dental students were asked to attend a lecture on dental trauma and then respond to an online questionnaire containing 10 close-ended questions related to their approach to managing dental trauma cases and tooth avulsion before (T0) and directly after (T1) the lecture. They were given $5 \mathrm{~min}$ for filling the questionnaire either time. McNemars test was used to compare the accuracy of their answers based on the correct or incorrect response for each question. The level of significance was set at $p<0.05$.

Results: The questionnaire was sent to 164 students, out of which 157 responded, giving a response rate of $95.7 \%$. After receiving the educational intervention, the students showed a significant improvement in their knowledge on managing permanent tooth avulsion, especially regarding the handling of an avulsed tooth before replantation, extra-alveolar time, and media used for the storage and transportation of avulsed teeth $(<0.001)$.

Conclusion: The study reveals that the lecture on dental trauma had an excellent outcome on the knowledge of the students. Therefore, it is essential to emphasize the importance of this information among undergraduate dental students in order to save teeth exposed to trauma and to reduce the social burden of such cases. This study contributes to better understanding of the effect of dental trauma education on undergraduate dental students' knowledge of the subject.

Keywords: dental trauma education, dental injuries, dental students

\section{Introduction}

Dental trauma is considered a major public health problem that might have a negative impact on the physical and psychological well-being of the affected individuals. ${ }^{1}$ It ranges from minor chipping of the enamel to major maxillofacial injuries that involve the supporting tooth structure, or even tooth avulsion, which represents $1-16 \%$ of dental trauma cases, with the highest occurrence in the maxillary central incisor. ${ }^{2,3}$ It is well known that the emergency management of an avulsed tooth is crucial for its survival. ${ }^{4}$ Thus, avulsion presents a challenge to the dental community. ${ }^{5-7}$

Unfortunately, most healthcare professionals cannot accurately perform the correct emergency procedure when they encounter a case of avulsion., ${ }^{8,9}$ These facts demonstrate a frightening situation of permanent damage to an avulsed tooth if
Department of Basic Medical and Dental Sciences, Centre of Medical and Bio-Allied Health Sciences Research, Ajman University, P.O. Box 346, Ajman, United Arab Emirates Tel +9716705 6394

Email r.hashim@ajman.ac.ae 
it is not properly treated. ${ }^{10}$ Consequently, it is essential for dental professionals to be well informed about the appropriate measures to prevent post-traumatic complications in such cases, since they are often requested to aid patients who have been in accidents involving tooth injury. ${ }^{11}$ Dental trauma is not a disease but an outcome of numerous inevitable risk factors. ${ }^{12}$ Traumatic dental injuries and their sequela may surpass the burden of dental caries and periodontal diseases among young people. ${ }^{13}$

Previous studies from the United Arab Emirates (UAE) have investigated knowledge of tooth avulsion and its management among mothers ${ }^{14}$ and school teachers; ${ }^{15}$ they clearly illustrate lack of experience and knowledge concerning the management of dental trauma, reflecting the need for more effective communication between dental professionals and their communities. Thus, it is imperative to teach the protocols of dental trauma emergency to undergraduate dental students to equip them with the required knowledge when they encounter such cases.

\section{Methods}

The current study was approved by the ethics committee of Ajman University (AU), under reference number (GD/ 6/2020). All AU fourth-year dental students enrolled during 2019-2020 academic year were eligible to take part in this study. It was conducted at the beginning of the 2020 academic year among fourth-year dental students at AU. Prior to its commencement, the students were informed about it, and their participation was voluntary. No identifying information was collected.

Microsoft Forms was used to create an online, selfadministered questionnaire in English. The survey questionnaire was adapted from Nagata et al, ${ }^{16}$ and Raoof et al. ${ }^{17}$ It consisted of two parts; the first was used to collect socio-demographic data on the participants, specifically, their age and gender, and the second included questions related to their knowledge and awareness of management of crown fracture and tooth avulsion of the teeth. The study was divided into three stages: pretest (at T0), interventional lecture, and posttest (at T1). The pretest and posttest were carried out before and immediately after the lecture, and the students were given 10 min to finish both. They received a 2-hours lecture in English (with a 10-min break) by one of the authors, which included instructions on clinical examinations, diagnoses, and treatment methods for fractured crowns and tooth avulsion based on guidelines of the
International Association for Dental Traumatology (IADT). ${ }^{11}$ A computer screen was used. The students had an open discussion before the posttest was conducted.

The questionnaire was pre-tested on 15 students before the start of the study to confirm that all questions were easily understood by the participants. Those students did not take part in the main study. The web link of the questionnaire (pretest and posttest) was distributed among all fourth-year dental students at AU through their email addresses, along with a covering letter clarifying the objective of the study and assuring the students of the anonymity of their answers. The average time taken to complete the questionnaire was about 4 minutes. The data were entered into Microsoft Excel and then transferred onto SPSS 23.0. Descriptive analysis was then performed to find the frequencies of the sociodemographic data, and McNemars test was used to compare the accuracy of the student's responses before and after the lecture. The significance level was set at $p<0.05$.

\section{Results}

In this interventional study, both phases of the questionnaire (pretest and posttest) were completed by 157 dental students out of the 164 to whom the survey was sent, at a response rate of $95.7 \%$. The remainder $(4.3 \%)$ either chose not to participate or were absent on the day of data collection. Around $64 \%$ of the participants were female. The majority (97\%) of the respondents were aged between 20 and 24 years (data not presented).

The answers obtained from the students before and after the lecture are presented in Table 1. Regarding the importance of carrying a fractured crown fragment to a dentist, $71 \%$ of them responded correctly at T0. However, only $30 \%$ could identify the correct transport media for the fragments. Nevertheless, there was a significant improvement $(p>0.05)$ in their knowledge from $\mathrm{T} 0$ to $\mathrm{T} 1$, with $95.5 \%$ of the students understanding the importance of carrying the fractured crown fragment to the dentist using water as the transport medium.

When the participants asked whether an avulsed primary tooth should be replanted, $94.9 \%$ of them at $\mathrm{T} 1$, compared to only $37.6 \%$ at $\mathrm{T} 0$, provided the correct answer. Similarly, the percentage of respondents providing the correct answer to the question, "Should an avulsed permanent tooth be replanted in its socket?" increased from $75.1 \%$ to $98.1 \%$ between $\mathrm{T} 0$ and T1. Most 
Table I Comparison of Students' Knowledge Before and After Receiving Dental Trauma Lecture ( $\mathrm{n}=\mid \mathbf{5 7})$

\begin{tabular}{|c|c|c|c|c|c|}
\hline Question (Correct Answer) & $\begin{array}{l}\text { Correct } \\
\text { Answer }\end{array}$ & $\begin{array}{l}\text { Incorrect } \\
\text { Answer }\end{array}$ & $\begin{array}{l}\text { Correct } \\
\text { Answer }\end{array}$ & $\begin{array}{l}\text { Incorrect } \\
\text { Answer }\end{array}$ & $\mathbf{P}$ \\
\hline $\begin{array}{l}\text { Carry fractured crown fragment to the dentist (Take the fragment to } \\
\text { the dentist) }\end{array}$ & $112(71.3)$ & $45(28.7)$ & $150(95.5)$ & $7(4.5)$ & 0.00 \\
\hline Fractured fragment transport medium (Milk or water) & $47(30.0)$ & $110(70.0)$ & $150(95.5)$ & $7(4.5)$ & 0.00 \\
\hline Replanting primary tooth (Not to be replanted) & $59(37.6)$ & $98(62.4)$ & $149(94.9)$ & $8(5.1)$ & 0.00 \\
\hline Replanting permanent tooth (Not in all cases) & $118(75.1)$ & $39(24.9)$ & $154(98.1)$ & $3(1.9)$ & 0.25 \\
\hline $\begin{array}{l}\text { Cleaning of contaminated avulsed tooth (Holding the crown and wash } \\
\text { it with sterile saline) }\end{array}$ & $107(68.2)$ & $50(31.8)$ & $157(100)$ & $0(0)$ & 0.02 \\
\hline
\end{tabular}

significantly, while at To only $68.2 \%$ of the students recognized that within the clinical setting a dirty avulsed tooth should be washed with saline before replantation, this figure reached $100 \%$ after the lecture (Table 1).

The pairwise comparison using McNemar's test showed that the students' knowledge regarding transport media was significantly different before and after the lecture (McNemar's test, $p<0.05$ ), as illustrated in Figure 1. A similar observation was made in relation to their understanding of the extraalveolar time of an avulsed tooth, as shown in Figure 2.

\section{Discussion}

This study was conducted at the beginning of the fourth academic year of undergraduate dental students at $\mathrm{AU}$ to assess their knowledge on dental trauma, specifically, tooth avulsion. These students had limited clinical experience in

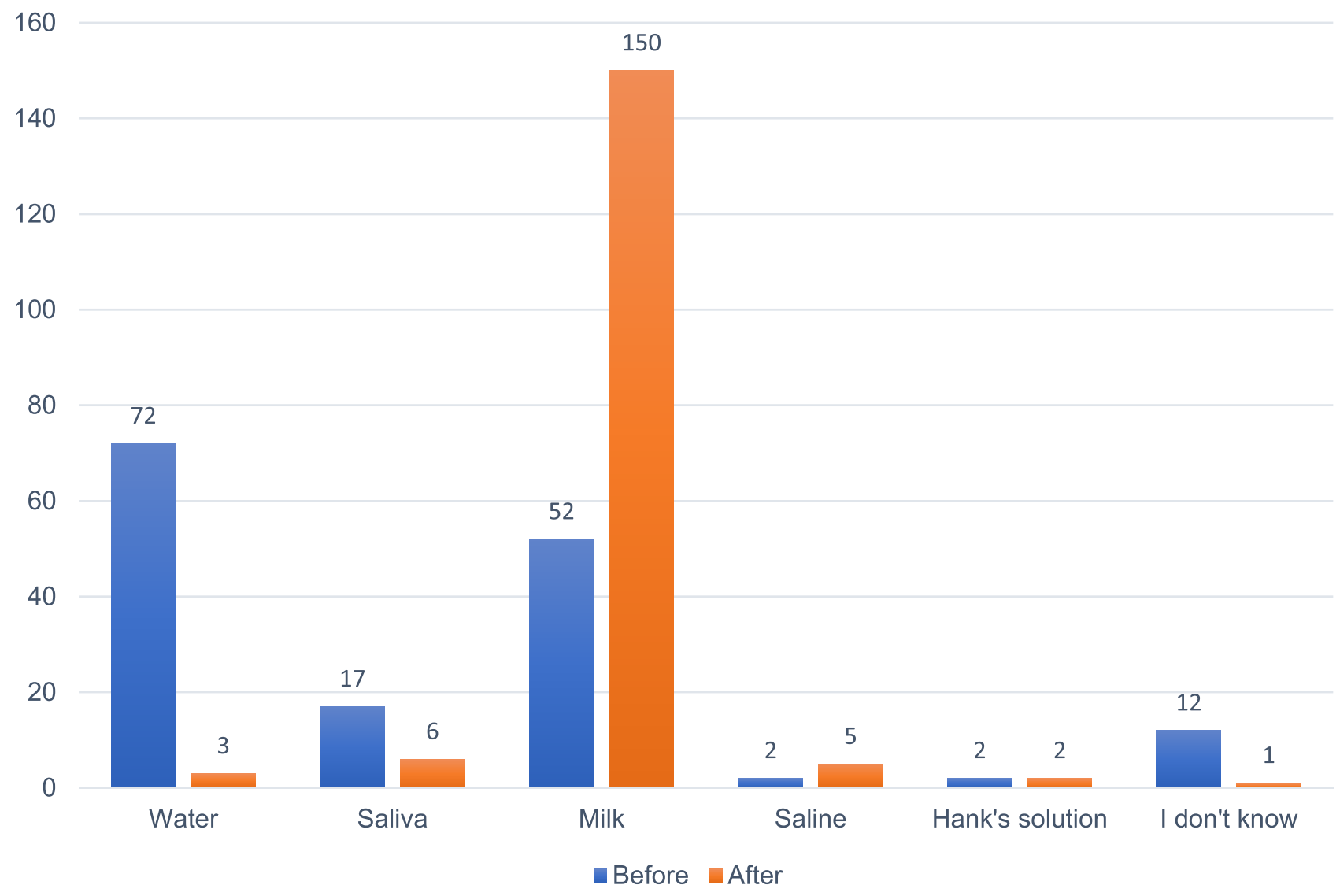

Figure I Knowledge regarding the transport media for an avulsed tooth before and after the intervention. 


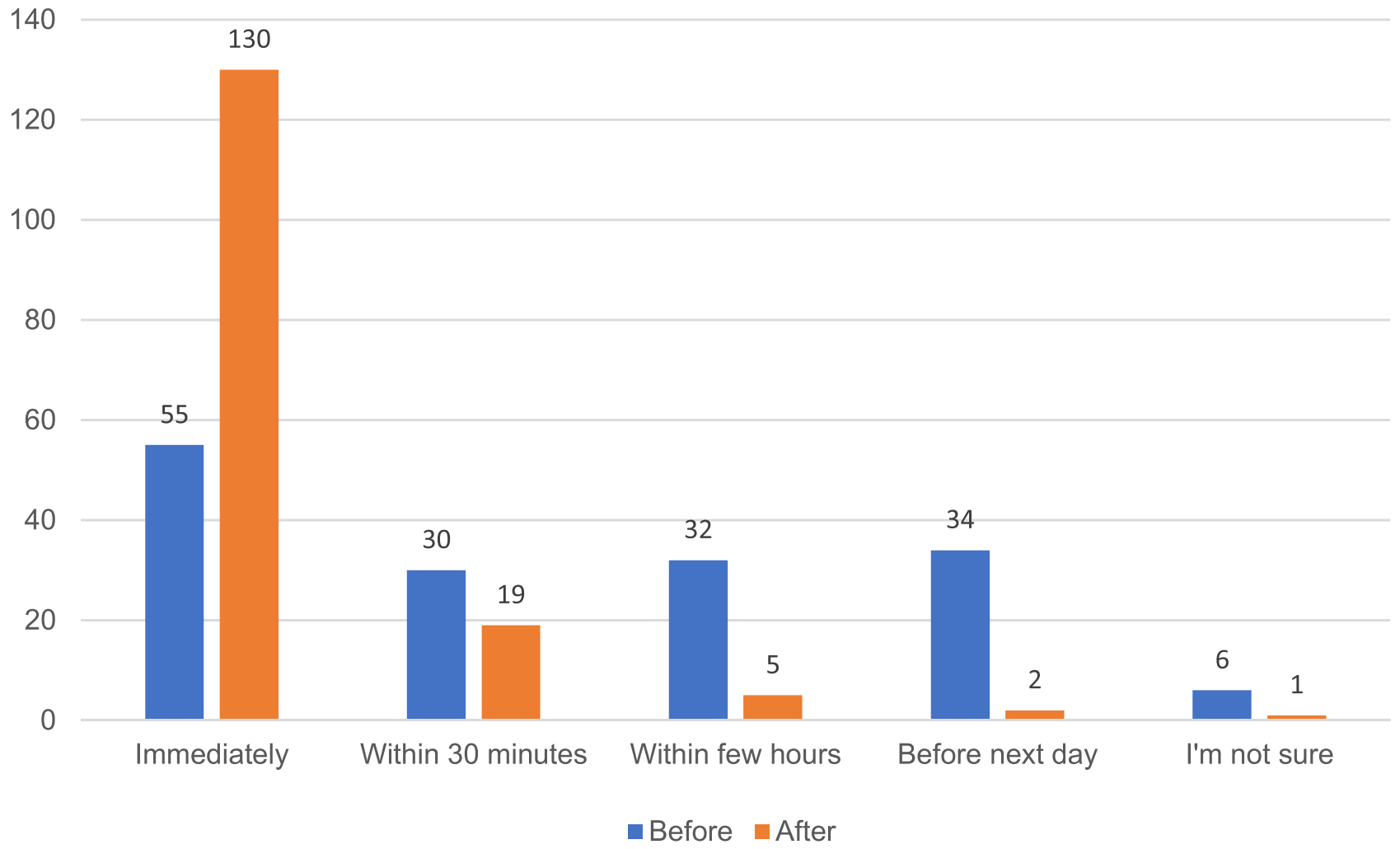

Figure 2 Knowledge regarding the extra alveolar time for an avulsed tooth before and after the intervention.

dentistry; therefore, it was reasonably assumed that their baseline knowledge of dental trauma would be minimal. The design of the study emphasized knowledge acquisition and did not anticipate clinical competence in handling dental trauma.

Overall, the current study demonstrates that the short lecture on dental trauma led to a significant improvement in the students' knowledge on the topic. Similar finding reported by Nagata et al, ${ }^{16}$ and Raoof et al. ${ }^{17}$ The online questionnaire was used to compare the baseline and post-lecture knowledge of the students regarding the correct procedures to follow when encountering dental trauma cases. To the best knowledge of the researchers, no such study has been conducted to evaluate the knowledge of undergraduate students and to examine the usefulness of the lecture format for teaching about dental trauma in the UAE.

The students demonstrated lack of knowledge concerning the management of dental trauma cases before the interventional lecture; about a quarter of the respondents were unable to identify the precise protocol to transport a fractured crown fragment, and only one-third were aware that the best way to transport such a fragment was under moist conditions. A dehydrated medium may affect the prognosis of the tooth. According to the IADT guidelines for dental trauma management, reattachment of the fractured fragment to the tooth is the first choice of action to achieve a better aesthetic and functional outcome for the traumatized tooth. ${ }^{18}$

In the pretest, approximately $63 \%$ of the participants stated that an avulsed primary tooth should be replanted, demonstrating a clear lack of knowledge in this area. Meanwhile, threequarters of the students answered that an avulsed permanent tooth should not be replanted in any cases, in agreement with the results of earlier studies. ${ }^{20,21}$ According to IADT, in cases where the patient is not cooperative, has a high level of caries, or is medically compromised, replantation of an avulsed permanent tooth is not advised. ${ }^{21}$ The study respondents' knowledge in this regard was clearly improved after the interventional lecture.

Additionally, while only around $68 \%$ of the students responded that under in a clinical setting, washing the avulsed tooth with physiological saline while holding it 
by the crown before replantation is the best way to handle it, this figure reached $100 \%$ after they received the lecture, showing clear variance between the T0 and T1 scores. This finding is consistent with Baginska and WilczynskaBorawska, ${ }^{22}$ who stated that in a clinic environment most of their respondents (85\%) would handle an avulsed tooth by rinsing it gently with saline. IADT recommends cleaning the root surface with saline in a situation where the avulsed tooth was either kept in a physiological storage medium or in a situation where the avulsed tooth kept dry and the extra-oral dry time did not exceed $60 \mathrm{~min}^{2}$

It is necessary to choose a suitable storage medium for maintaining the "vitality" of periodontal ligament cells (PDL) and consequently avoiding further damage to the tooth. Before they received the interventional lecture, there was a difference of opinion among the students concerning the storage medium to be used for an avulsed tooth. The majority of them (46\%) stated water was the best storage medium, followed by those who responded with milk (33\%) and the patient's saliva (11\%). This finding contradicts the results of earlier studies in which most of the respondents stated that the patient's saliva, ${ }^{23}$ saline, ${ }^{22}$ or milk ${ }^{24}$ would be the preferable or recommended storage medium. However, at T1, 95.5\% of the students correctly identified milk as the ideal storage medium for an avulsed tooth-milk is easy to obtain in the event of an accident, and it can maintain PDL cells. ${ }^{25}$ A substantial number of studies show that milk is superior to saline in preserving vitality, both in vitro and in vivo. ${ }^{26-28}$

Following the precise post-traumatic emergency management protocol can help improve the short- and long-term prognosis of an avulsed tooth. ${ }^{13}$ In the current study, after receiving the interventional lecture, most of the respondents (95\%) reported that the ideal extraoral period for an avulsed tooth is less than $30 \mathrm{~min}$; extending it beyond this point may affect the replantation, as indicated by previous studies. ${ }^{19,20,23}$ According to Andreasen et al, ${ }^{21}$ replanting a tooth within $30 \mathrm{~min}$ will lead to a more favorable prognosis compared to doing so after a longer extraoral time.

To some extent, the significant increase in the students' knowledge of handling tooth avulsion after the intervention was anticipated and can be attributed to the lecture; the results indicate that a lecture is an effective medium for improving knowledge of dental trauma management among undergraduate dental students. However, numerous studies $^{29,30}$ have reported a significant decrease in dental trauma knowledge with time, emphasizing the importance of supplementary lectures using various educational approaches, such as problem-based learning.
The responsibility of the dental practitioner is not limited to treating trauma cases but also includes spreading awareness about preventing and managing dental trauma in their society, ${ }^{22}$ because emergency intervention in such cases should commence at the location of the injury rather than at the dental clinic. ${ }^{12}$ Such an approach will decrease the undesirable outcomes of such incidents and will have a positive impact on their social costs in the long run. Thus, educational programs targeting the development of dental students' knowledge regarding the accurate management of dental trauma might be the first step to prevent complications from such cases.

The limitations of this study should be considered when interpreting the findings. A main constraint was the sampling methodology applied in this study. The convenience sample used here may not adequately represent all dental students in the UAE. Additionally, due to one-group selection for the pretest-posttest design of the study, there is no guarantee that the knowledge improvement was a direct outcome of the interventional lecture. Another limitation is that there was a chance of selection bias; the dental students who participated in this study might have been more interested in dental trauma management than those who chose not to participate. Therefore, the results cannot be generalized to all students, although the percentage of nonrespondents was extremely low. However, despite these limitations, the study provides some important information concerning the impact of dental education on dental students' knowledge regarding the management of dental trauma in the UAE.

\section{Conclusion}

The study participants showed insufficient knowledge concerning the management of a fractured tooth fragment and tooth avulsion at the baseline. However, there was an encouraging enhancement in their knowledge from T0 to T1. Knowledge retention is critical in the management of trauma cases; therefore, further research is recommended to examine the long-term retention of knowledge gained from an interventional lecture, because the acquired information might gradually decreases over time, necessitating frequent reminder lectures.

\section{Data Sharing Statement}

The datasets used and/or analyzed during the current study are available from the corresponding author on reasonable request. 


\section{Ethics Approval and Consent to Participate}

The authors confirm that this research has been conducted in full accordance with the World Medical Association Declaration of Helsinki. The current study was approved by the ethics committee of Ajman University (AU). Written informed consent was obtained from all participants included in the study, and the anonymity of the participants was ensured.

\section{Acknowledgments}

The authors would like to acknowledge all the undergraduate students participated in this study, and the support of Ajman University for their contribution in the Article Processing Charges.

\section{Author Contributions}

All authors made a significant contribution to the work reported, whether that is in the conception, study design, execution, acquisition of data, analysis and interpretation, or in all these areas; took part in drafting, revising or critically reviewing the article; gave final approval of the version to be published; have agreed on the journal to which the article has been submitted; and agree to be accountable for all aspects of the work.

\section{Funding}

This study was not supported or funded by any research grants.

\section{Disclosure}

The authors declare that they have no conflicts of interest with respect to the submitted work.

\section{References}

1. Mustafa M. Awareness about management of tooth avulsion among general dental practitioners: a questionnaire based study. J Orthod Endod. 2017;3:1.

2. Levin L, Day PF, Hicks L, et al. International Association of Dental Traumatology guidelines for the management of traumatic dental injuries: general introduction. Dent Traumatol. 2020;36 (4):309-313.

3. Petti S, Glendor U, Andersson L. World traumatic dental injury prevalence and incidence, a meta-analysis-one billion living people have had traumatic dental injuries. Dent Traumatol. 2018;34(2):71-86.

4. Moule A, Cohenca N. Emergency assessment and treatment planning for traumatic dental injuries. Aust Dent J. 2016;61(Suppl 1):21-38.

5. Bahammam LA. Knowledge and attitude of emergency physician about the emergency management of tooth avulsion. BMC Oral Health. 2018;18(1):57.
6. Enabulele JE, Enabulele O, Nwashilli N. Knowledge of hospital emergency unit staff about the first-aid management of traumatic tooth avulsion in a tertiary hospital in Nigeria. EC Dental Sci. 2016;5(3):1082-1089.

7. Kostopoulou MN, Duggal MS. A study into dentists' knowledge of the treatment of traumatic injuries to young permanent incisors. Int J Paediatr Dent. 2005;15(1):10-19.

8. Ravikumar D, Jeevanandan G, Subramanian EMG. Evaluation of knowledge among general dentists in treatment of traumatic injuries in primary teeth: a cross-sectional questionnaire study. Eur J Dent. 2017;11(2):232-237.

9. Hashim R. Physicians' knowledge and experience regarding the management of avulsed teeth in United Arab Emirates. J Int Dent Med Res. 2012;5(2):91-95.

10. Wang G, Wang C, Qin M. A retrospective study of survival of 196 replanted permanent teeth in children. Dent Traumatol. 2019;35(45):251-258.

11. Fouad AF, Abbott PV, Tsilingaridis G, et al. International Association of Dental Traumatology guidelines for the management of traumatic dental injuries: 2. Avulsion of permanent teeth. Dent Traumatol. 2020;36(4):331-342.

12. Lam R. Epidemiology and outcomes of traumatic dental injuries: a review of the literature. Aust Dent J. 2016;61(Suppl 1):4-20.

13. Flores MT, Andersson L; International Association of Dental Traumatology, et al.. Guidelines for the management of traumatic dental injuries. II. Avulsion of permanent teeth. Dent Traumatol. 2007;23(3):130-136.

14. Hashim R. Investigation of mothers' knowledge of dental trauma management in United Arab Emirates. Eur Arch Paediatr Dent. 2012;13(2):83-86.

15. Hashim R. Dental trauma management awareness among primary school teachers in the Emirate of Ajman, United Arab Emirates. Eur J Paediatr Dent. 2011;12(2):99-102.

16. Nagata JY, Góis VLA, Münchow EA, Albuquerque MTP. Dental trauma education intervention as a positive influence among undergraduate students. Eur J Dent. 2018;12(4):502-507.

17. Raoof M, Shokouhinejad N, Izadi A, et al. Long-term effect of an educational intervention regarding dental trauma first aid: a Phase II study. Dent Traumatol. 2014;30(4):296-301.

18. Diangelis AJ, Andreasen JO, Ebeleseder KA, et al.; International Association of Dental Traumatology. International Association of Dental Traumatology guidelines for the management of traumatic dental injuries: 1. Fractures and luxations of permanent teeth. Dent Traumatol. 2012;28(1):2-12.

19. Zhao Y, Gong Y. Knowledge of emergency management of avulsed teeth: a survey of dentists in Beijing, China. Dent Traumatol. 2010;26 (3):281-284.

20. Cohenca N, Forrest JL, Rotstein I. Knowledge of oral health professionals of treatment of avulsed teeth. Dent Traumatol. 2006;22 (6):296-301.

21. Andersson L, Andreasen JO, Day P, et al.; International Association of Dental Traumatology. International Association of Dental Traumatology guidelines for the management of traumatic dental injuries: 2. Avulsion of permanent teeth. Dent Traumatol. 2012;28 (2):88-96.

22. Baginska J, Wilczynska-Borawska M. Continuing dental education in the treatment of dental avulsion: polish dentists' knowledge of the current IADT guidelines. Eur J Dent Educ. 2013;17(1):e88-92.

23. Westphalen VP, Martins WD, Deonizio MD, da Silva Neto UX, da Cunha CB, Fariniuk LF. Knowledge of general practitioners dentists about the emergency management of dental avulsion in Curitiba, Brazil. Dent Traumatol. 2007;23(1):6-8.

24. de Vasconcellos LG, Brentel AS, Vanderlei AD, de Vasconcellos LM, Valera MC, de Araújo MA. Knowledge of general dentists in the current guidelines for emergency treatment of avulsed teeth and dental trauma prevention. Dent Traumatol. 2009;25(6):578-583. 
25. Flores MT, Andreasen JO, Bakland LK, et al.; International Association of Dental Traumatology. Guidelines for the evaluation and management of traumatic dental injuries. Dent Traumatol. 2001;17(1):1-4.

26. Silva EJ, Rollemberg CB, Coutinho-Filho TS, Krebs RL, Zaia AA. Use of soymilk as a storage medium for avulsed teeth. Acta Odontol Scand. 2013;71(5):1101-1104.

27. Gjertsen AW, Stothz KA, Neiva KG, Pileggi R. Effect of propolis on proliferation and apoptosis of periodontal ligament fibroblasts. Oral Surg Oral Med Oral Pathol Oral Radiol Endod. 2011;112(6):843-848.
28. Dos Santos CL, Sonoda CK, Poi WR, Panzarini SR, Sundefeld ML, Negri MR. Delayed replantation of rat teeth after use of reconstituted powdered milk as a storage medium. Dent Traumatol. 2009;25(1):51-57.

29. Cauwels RG, Martens LC, Verbeeck RM. Educational background of Flemish dental practitioners and their perceptions of their management of dental trauma. Dent Traumatol. 2014;30(2):133-139.

30. de França RI, Traebert J, de Lacerda JT. Brazilian dentists' knowledge regarding immediate treatment of traumatic dental injuries. Dent Traumatol. 2007;23(5):287-290.

\section{Publish your work in this journal}

Advances in Medical Education and Practice is an international, peerreviewed, open access journal that aims to present and publish research on Medical Education covering medical, dental, nursing and allied health care professional education. The journal covers undergraduate education, postgraduate training and continuing medical education including emerging trends and innovative models linking education, research, and health care services. The manuscript management system is completely online and includes a very quick and fair peer-review system. Visit http://www.dovepress.com/testimonials.php to read real quotes from published authors. 